\title{
Characterization of osteoarthritis in patients with diabetes mellitus type 2
}

\author{
Elena V Zonova ${ }^{2}$, Alexander P Lykov ${ }^{1 *}$, Elena P Trifonova ${ }^{1}$ and Olga V Sazonova ${ }^{1}$ \\ ${ }^{1}$ Federal State Budgetary Scientific Institution Scientific Institute of Clinical and Experimental Lymphology, Novosibirsk \\ ${ }^{2}$ Federal Budgetary Education Institution of Higher Professional Education Novosibirsk State Medical University Department of Health of Russian Federation, \\ Novosibirsk
}

\begin{abstract}
Investigation of the clinical and pathogenesis aspects of osteoarthritis in combinations with diabetes mellitus type 2 . Were studied 80 patients with osteoarthritis, 52 of them has a comorbidity disease such as diabetes mellitus type 2 . Were investigated the clinical and radiological signs of disease severity, the levels of cytokines, NO, leptin, and CRP in serum, and levels of blood glucose, and levels of glycated hemoglobin, and SSE. Were found significant differences in body weight, data of ESR, features functional status of the joints and the quality of life in patients with osteoarthritis in combination with type 2 diabetes compared with those without the metabolic disturbance. Moreover, in patients with osteoarthritis of comorbidity for T2DM was established elevated level of IL-6, IL-18, NO and leptin in serum. Were determined differences in the features of the clinical symptoms of osteoarthritis in patients with type 2 diabetes based on blood glucose level, and data of glycated hemoglobin. Were obtained some correlations between of the levels of cytokines in the blood serum with the parameters of the functional status of the joints, and with the quality of life in patients with osteoarthritis in combination with type 2 diabetes. Osteoarthritis in combinations with diabetes mellitus type 2 characterized by a more pronounced severity of clinical symptoms, and functions impairment.
\end{abstract}

\begin{abstract}
Abbreviations: OA: osteoarthritis; T2DM: diabetes mellitus type 2; IL-1 $\beta$ : interleukin 1 beta; IL-6: interleukin 6; IL-10: interleukin 10; IL-18: interleukin 18; TNF-a: tumor necrosis factor alpha; NO: nitrite oxide; CRP: C-reactive protein; SSE: subsidence of erythrocytes; BWI: body weight index
\end{abstract}

\section{Introduction}

Diabetes mellitus (DM) is affected more than 180 million people worldwide [1]. DM type 2 (T2DM) is combined functional insufficiency of $\beta$-cells and resistance to insulin. The excess of hyperglycemia leads to development of a metabolic syndrome which initiates a chronic inflammation in patients with T2DM [2]. Osteoarthritis (OA) is the most common joint disorder in peoples with 60 years or more in worldwide, moreover, on elder people often presents the combination of OA and T2DM [3-4]. Some researcher, allocate a special phenotype of OA "diabetes-induced OA phenotype" [5]. Both of these pathologies are characterized by a chronic current, association with age and obesity [6]. It is shown that existence of T2DM in patients with OA exerts impact on clinical efficiency [3]. In pathogenesis of T2DM and OA the essential part is assigned to cytokines [7-8]. So, dysfunction of $\beta$-cells at T2DM is caused by the inflammatory reaction initiated by IL- $1 \beta$ and NFkB. At T2DM are raised the IL- $1 \beta$, and IL- 12 levels, and CCL2, and CCL13 [2]. In patients with OA found increased levels of pro-inflammatory cytokines (IL-6, TNF- $\alpha$ ). It is known that pro-inflammatory cytokines promote $\mathrm{OA}$ emergence/progression, indirectly through change of levels of an expression of genes of MMP, through stimulation of production of ROS, through changes a metabolism in chondrocytes, and also through activation an osteoblast - the mediated resorption of a bone tissue [8]. The disorders in lipid metabolism and hyperglycemia can directly influence a metabolism in cartilage, bone tissue and serve as triggers of development of $\mathrm{OA}$ in patients with T2DM [4].

The aim of the present study was to evaluate clinical and pathogen aspects of $\mathrm{OA}$ in patients with T2DM.

\section{Materials and methods}

This study was approved by the Ethics Committee for Analysis of Research Project of Institute of Clinical and Experimental Lymphology, and Medical State University, Novosibirsk, Russia. All participants were informed about the study procedure and signed consent to participate in this study. We recruited 80 patients aged 44 76 years. Patients were enrolled sequentially, with the first 28 patients assigned to the OA group and the last 52 patients to the OA+T2DM group. Groups of patients were comparable on age, sex and duration of OA. The verification of OA was carried out X-ray analysis of joints with the subsequent assessment on a scale of Kellgren-Lawrence and OARSI. The functional status of joints was estimated on a scale of FIHOA (Functional Index of Hand OA), KOOS/HOOS (Knee/ Hip injury and Osteoarthritis Outcome Score), WOMAC Knee, Hip (Western Ontario and McMaster Universities Arthritis Index). For an assessment of WOMAC and KOOS/HOOS used visual analog $100 \mathrm{~mm}$ of a subscale. The total WOMAC index represents the sum of subscales of pain, constraint and malfunction on WOMAC. High

Correspondence to: Alexander P Lykov, Laboratory of Cellular Technology, Scientific Institute of Clinical and Experimental Lymphology, 2, Timakova Str., Novosibirsk, Russia, 630060, E-mail: aplykov2@mail.ru

Key words: osteoarthritis, diabetes mellitus type 2, cytokines, blood glucose level, glycated hemoglobin, functional status and quality of life

Received: April 28, 2016; Accepted: May 10, 2016; Published: May 14, 2016 
WOMAC values reflect high severity of OA. KOOS/HOOS indicators also transformed to a scale from 0 to 100 , at the same time the shift of values to the right on a scale indicates smaller expressiveness of pain and symptoms, and also smaller decline in quality of life of patients. Quality of life of patients (level of pain, depression, the general health, "a coping strategy" overcoming of pain) was estimated on a scale of SF-36 (Short form of index quality of life), VAS (visual analog scale), PHQ-9 and CSQ. Anthropometric research included determination of weight, volume of a waist and calculation of the body weight index (BWI). For dosage of the concentration of serum cytokines, a blood sample $(5 \mathrm{~mL})$ was taken from cubital vein between $8 \mathrm{am}$ and $10 \mathrm{am}$. The sera samples were obtained after centrifugation at $500 \mathrm{~g}$ and $4^{\circ} \mathrm{C}$ and aliquoted in Eppendorf Cryotubes (Hamburg, Germany) and stored at $-80^{\circ} \mathrm{C}$ until use. A human ELISA for IL-1 $\beta$, IL-6, IL-10, IL-18 (Vector, Novosibirsk) and Leptin ELISA (Diagnostics Biochem, Canada) was used to quantitatively measure serum concentrations according to the manufacturer's instructions. To determine amount of nitrites and nitrates in the serum nitrite oxide (NO) inhibition assay was conducted using Griess reagent kit for nitrite determination (Molecular Probes). The amount of $\mathrm{NO}$ was calculated using a sodium nitrite standard curve. Level of $C$ reactive protein (CRP) in serum defined with use of a set of the Vital Development Corporation (Russia). Levels of the speed of subsidence of erythrocytes (SSE) investigated on Vestegren. Levels of glycated hemoglobin (Hgb A1s) estimated by means of a calorimetric method on the Specol device (Carl Zeiss, Germany). Sugar of blood was investigated with use of a glucometer of AccuCheck Advantage (Roche; Germany). The Kolmogorov-Smirnov adjustment test for a normal distribution for all study variables was used. Quantitative characteristics of the patients were described in two groups with the use of median, lower and upper quartiles. Statistical comparisons were made between patients with $\mathrm{OA}$ and $\mathrm{OA}+\mathrm{DM}-2$ by Mann-Whitney $U$ test where data were not normally distributed. The correlation between data was done by Spirmen (r). Data analysis was done by Statistica 10.0 (Stat Soft, USA). Statistical significance was set at $\mathrm{P}<0.05$, two tailed.

\section{Results}

The study includes 28 patients with OA (23 females and 5 males, aged 44-76) and 52 patients with $\mathrm{OA}+\mathrm{T} 2 \mathrm{DM}$ ( 42 females and 10 males, aged 52-76). Table 1 shows that patients with combination OA and DM-2 were on average statistically heavy (body weight, volume of a waist, and $\mathrm{BWI})$ than patients with $\mathrm{OA}(\mathrm{P}<0.05)$. Also, patients with combination OA and T2DM had a statistically significant increased SSE compared to patients with $\mathrm{OA}(\mathrm{P}<0.05)$. Other baseline characteristics of OA activity, such as the pain, overall health, morning stiffness, and assessment of disease the doctor on VAS scale was statistically significantly differ between groups $(\mathrm{P}<0.05)$. Moreover, we found statistically significant differ on functional status of joints (KOOS, WOMAC), and quality of life of patients (SF-36, and PHQ-9) between groups $(\mathrm{P}<0.05)$. On age, height, and duration of illness of $\mathrm{OA}$ did not differ statistically between groups $(\mathrm{P}>0.05)$.

Thus, patients with combination OA and T2DM are characterized by tendency to obesity and more expressed clinical manifestation of OA (morning stiffness, changes in general health), and also more expressed decline in quality of life.

In table 2 summarized the levels in blood serum biological active agents involved in pathogenesis of OA and T2DM. So, in patients with combination $\mathrm{OA}$ and T2DM observed statistically significant higher levels of IL-6, and IL-18, and NO, and leptin compared to patients with $\mathrm{OA}(\mathrm{P}<0.05)$.
Table 1. The characteristic of patients with OA and with combination of OA and T2DM.

\begin{tabular}{|c|c|c|}
\hline Parameters & $\mathrm{OA}(\mathrm{n}=28)$ & $\mathrm{OA}+\mathrm{T} 2 \mathrm{DM}(\mathrm{n}=52)$ \\
\hline Age (years) & $63.5(55-67.5)$ & $63(58.5-69)$ \\
\hline Height $(\mathrm{cm})$ & $164(159-168)$ & $162(158-167)$ \\
\hline Weight (kg) & $75(68.5-79.2)$ & $92.5(82.5-102.2)^{*}$ \\
\hline BWI $\left(\mathrm{kg} / \mathrm{m}^{2}\right)$ & $28.3(25.4-31.3)$ & $33.5(31.2-38.2)^{*}$ \\
\hline Waist circumference $(\mathrm{cm})$ & $87(81-95)$ & $106.5(100-116.5)^{*}$ \\
\hline Duration of illness T2DM (years) & 0 & $8(5-12.5)$ \\
\hline Duration of illness OA (years) & $6(3-8.5)$ & $4(3-8)$ \\
\hline $\mathrm{SSE}$ (mm/hour) & $12(5-15)$ & $23(13-33)^{*}$ \\
\hline Generalized OA (\%) & 100 & 100 \\
\hline Coxarthrosis коксартроз (\%) & 58 & 68 \\
\hline Gonarthrosis (\%) & 100 & 100 \\
\hline Nodules of Heberden/Bouchard (\%) & 67 & 75 \\
\hline Pain on scale VAS (mm) & $48(35.2-50)$ & $59(48-70)^{*}$ \\
\hline Overall health on scale VAS (mm) & $47(27-50)$ & $54(47.5-71.5)^{*}$ \\
\hline Morning stiffness (minutes) & $30(10-60)$ & $60(40-150)^{*}$ \\
\hline $\begin{array}{l}\text { Assessment of disease the doctor on scale VAS } \\
(\mathrm{mm})\end{array}$ & $41(33-51)$ & $53.5(43.5-50.5)^{*}$ \\
\hline KOOS symptoms & $77.7(70.1-86.1)$ & $58.3(50-70.8)^{*}$ \\
\hline KOOS pain level & $51.7(30.3-71.4)$ & $32.1(21.4-51.8)^{*}$ \\
\hline KOOS quality of life & $43.7(37.4-56.2)$ & $31.2(18.7-43.7)^{*}$ \\
\hline WOMAC total index & $\begin{array}{c}710.5(574.8- \\
1142)\end{array}$ & $\begin{array}{c}1338(950.3- \\
1546)^{*}\end{array}$ \\
\hline SF-36 physical well-being & $40(26.2-60)$ & $25(15-40)^{*}$ \\
\hline SF-36 general health & $47.5(37.7-65.5)$ & $32.5(25-45)^{*}$ \\
\hline SF-36 mental health & $62(49-71)$ & $48(32-56)^{*}$ \\
\hline PHQ-9 level of depressive disorders & $7(5-11)$ & $10(6-14)^{*}$ \\
\hline
\end{tabular}

Note: $*$ - statistical differ $\mathrm{p}<0.05$.

Table 2. The levels of biologically active agents in serum in patients with OA or combination $\mathrm{OA}$ and $\mathrm{T} 2 \mathrm{DM}$.

\begin{tabular}{|c|c|c|}
\hline Parameters & OA $(\mathrm{n}=28)$ & OA + T2DM $(\mathrm{n}=52)$ \\
\hline CRP $(\mathrm{mg} / \mathrm{mL})$ & $0(0-11.4)$ & $0(0-10.9)$ \\
\hline Leptin $(\mathrm{pg} / \mathrm{mL})$ & $24.5(13.8-44.7)$ & $47.8(27.4-59.3)^{*}$ \\
\hline NO $(\mu \mathrm{M} / \mathrm{mL})$ & $70(41.3-102.7)$ & $115.2(79.7-189.1)^{*}$ \\
\hline $\mathrm{IL}-1 \beta(\mathrm{pg} / \mathrm{mL})$ & $24.6(19.2-30)$ & $28.1(18,8-40.6)$ \\
\hline $\mathrm{IL}-6(\mathrm{pg} / \mathrm{mL})$ & $0.7(0.4-2.3)$ & $1.9(1-3.3)^{*}$ \\
\hline $\mathrm{IL}-10(\mathrm{pg} / \mathrm{mL})$ & $13.9(10.7-18)$ & $14.9(12.1-19.3)$ \\
\hline $\mathrm{IL}-18(\mathrm{pg} / \mathrm{mL})$ & $62.2(49.5-93.6)$ & $108.6(75.4-147.5)^{*}$ \\
\hline
\end{tabular}

Note: $*$ - statistical differ $\mathrm{p}<0.05$.

Only in 7 patients with combination OA and T2DM glucose level in blood didn't exceed $6 \mathrm{mM} / \mathrm{L}(13,46 \%)$. Proceeding of this fact, we analyzed clinical, functional and biochemical parameters in $\mathrm{OA}+$ T2DM group taking into account glucose level in blood lower or higher $6 \mathrm{mM} / \mathrm{L}$ (Table 3).

In patients with lower glucose level in blood statistically significant differ on duration of illness T2DM and duration of illness OA, and on the level of $\mathrm{Hgb} \mathrm{A} 1 \mathrm{c}$ in serum compare to patients with higher level of glucose in blood $(\mathrm{P}<0.05)$. Other baseline characteristics of OA didn't differ between patients with lower or patients with higher glucose levels in blood $(\mathrm{P}>0.05)$.

Other indicator of the severity of the T2DM in patients is the $\mathrm{Hgb}$ A1c level in blood [9]. We have carried out the analysis of clinical and biochemical parameters in group of patients with combination $\mathrm{OA}$ and T2DM depending on the Hgb Alc level less than $8 \%$ and more than $8 \%$ in blood (Table 4). Patients with Hgb A1c level less than $8 \%$ had statistically significant lower duration of illness of DM-2 and duration 
Table 3. The characteristic of patients with combination OA and T2DM under different glucose level in blood.

\begin{tabular}{|l|c|c|}
\hline \multirow{2}{*}{ Parameters } & \multicolumn{2}{|c|}{ Glucose level in blood } \\
\cline { 2 - 3 } & $<6 \mathrm{MM} / \mathrm{L}(\mathrm{n}=7)$ & $\emptyset \quad 6 \mathrm{MM} / \mathrm{L}(\mathrm{n}=45)$ \\
\hline Age $($ years $)$ & $63(55-70)$ & $63(59-69)$ \\
\hline Height $(\mathrm{cm})$ & $160(158-167)$ & $162(158-167)$ \\
\hline Weight $(\mathrm{kg})$ & $91(83-126)$ & $94(82-102)$ \\
\hline BWI $\left(\mathrm{kg} / \mathrm{m}^{2}\right)$ & $33.3(33,2-46,4)$ & $34,1(31-37.9)$ \\
\hline Waist circumference $(\mathrm{cm})$ & $106(96-128)$ & $107(100-116)$ \\
\hline Duration of illness T2DM (years) & $3(3-5)^{*}$ & $10(5-13)$ \\
\hline Duration of illness OA (years) & $2(2-3)^{*}$ & $5(3-8)$ \\
\hline Hgb A1c $(\%)$ & $6.3(0-6.6)^{*}$ & $7.6(6.1-8.8)$ \\
\hline CRP $(\mathrm{mg} / \mathrm{mL})$ & $0(0-11.3)$ & $0(0-10.6)$ \\
\hline Leptin $(\mathrm{pg} / \mathrm{mL})$ & $57.9(40.9-99.4)$ & $47.2(26.9-58.1)$ \\
\hline NO $(\mu \mathrm{M} / \mathrm{mL})$ & $101.5(64.7-134.5)$ & $125.4(81.3-209.2)$ \\
\hline IL-1 $(\mathrm{pg} / \mathrm{mL})$ & $28.9(17.8-30.8)$ & $28(19.8-40.9)$ \\
\hline IL-6 $(\mathrm{pg} / \mathrm{mL})$ & $1(0.1-2.4)$ & $2.2(1.4-3.5)$ \\
\hline IL-10 $(\mathrm{pg} / \mathrm{mL})$ & $15.4(13.5-22.6)$ & $14.9(12.1-19.3)$ \\
\hline IL-18 $(\mathrm{pg} / \mathrm{mL})$ & $96.7(63,6-161,4)$ & $116.9(76.5-144.4)$ \\
\hline
\end{tabular}

Note: $*$ - statistical differ $\mathrm{p}<0.05$

Table 4. Clinical features of the patients with combination OA and T2DM under blood levels of $\mathrm{Hgb}$ A1c.

\begin{tabular}{|l|c|c|}
\hline \multirow{2}{*}{ Parameters } & \multicolumn{2}{|c|}{ Hgb A1c level in blood } \\
\cline { 2 - 3 } & $>8 \%(\mathrm{n}=34)$ & $<8 \%(\mathrm{n}=16)$ \\
\hline Age $($ years $)$ & $65(58-69)$ & $63(59-68)$ \\
\hline Height $(\mathrm{cm})$ & $160.5(156-170)$ & $164(160-167)$ \\
\hline Weight $(\mathrm{kg})$ & $89(79-100)$ & $100(86-103)$ \\
\hline BWI $\left(\mathrm{kg} / \mathrm{m}^{2}\right)$ & $33.3(30.8-37,9)$ & $37.2(32.9-39.7)$ \\
\hline Waist circumference $(\mathrm{cm})$ & $106(100-114)$ & $109(105-119)$ \\
\hline Duration of illness T2DM (years) & $7(4-11)^{*}$ & $11(7-15)$ \\
\hline Duration of illness OA (years) & $4(2-6)^{*}$ & $8(3-10)$ \\
\hline Glucose level in blood (MM/L) & $7(6.2-8)^{*}$ & $9(8-10.9)$ \\
\hline SSE $(\mathrm{mm} / \mathrm{hour})$ & $25(12-31)$ & $21(14-35)$ \\
\hline CRP $(\mathrm{mg} / \mathrm{mL})$ & $0(0-10.6)$ & $0(0-14.1)$ \\
\hline Leptin $(\mathrm{pg} / \mathrm{mL})$ & $49.2(31.2-68.7)$ & $43.8(24.9-53.9)$ \\
\hline NO $(\mu \mathrm{MM} / \mathrm{mL})$ & $107.1(73.6-180.9)$ & $141.9(108.4-218)$ \\
\hline IL-1 $(\mathrm{pg} / \mathrm{mL})$ & $27.9(17.8-37.2)$ & $31(19.8-43.4)$ \\
\hline IL-6 $(\mathrm{pg} / \mathrm{mL})$ & $1.9(0.9-2.9)$ & $1.9(1.4-4.4)$ \\
\hline IL-10 $(\mathrm{pg} / \mathrm{mL})$ & $14.4(11.2-16.3)^{*}$ & $19(14.2-22.6)$ \\
\hline IL-18 $(\mathrm{pg} / \mathrm{mL})$ & $108.1(85.2-160.3)$ & $116.9(74.2-138.3)$ \\
\hline Overall health on scale VAS $(\mathrm{mm})$ & $50(46-69)^{*}$ & $66(52-73)$ \\
\hline KOOS symptoms & $61.1(52.7-77.8)^{*}$ & $50(50-63.9)$ \\
\hline KOOS quality of life & $37.5(18.7-50)^{*}$ & $25(12.5-31.2)$ \\
\hline SF-36 mental health & $52(40-64)^{*}$ & $36(24-48)$ \\
\hline PHQ-9 level of depressive disorders & $10(4-13)^{*}$ & $12(10-18)$ \\
\hline Note: $-5 a t i c a t ~$ & \\
\hline
\end{tabular}

Note: $*$ - statistical differ $\mathrm{p}<0.05$

of illness of OA, and glucose level in blood compare with patients whom had a higher level of Hgb A1c in blood $(\mathrm{P}<0.05)$. Also, for patients with lower level in blood of $\mathrm{Hgb} \mathrm{Alc}$ is typically lower levels of IL-10 in serum $(P<0.05)$. Moreover, we estimated statistically significant differ on functional status of joints (KOOS, WOMAC), and quality of life of patients (SF-36, and PHQ-9) compared to patients with a higher blood level of $\mathrm{Hgb} \mathrm{Alc}(\mathrm{P}<0.05)$.

The correlation analysis of the patients with combination OA and T2DM has revealed direct high and statistically significant interrelation of duration of illness T2DM and OA $(r=0,79 ; p=0,0000001)$, what indirectly confirms the available risk of development of $\mathrm{OA}$ in patients with T2DM. Moreover, glucose blood levels are associated with OA disease duration $(r=0,45 ; p=0,0007)$.
The interrelation of anthropometrical indicators with levels of a leptin and IL- 6 is shown. So, the level of leptin was negatively correlated with heights $(\mathrm{r}=-0,44 ; \mathrm{p}=0,0008)$ and positively correlated with body weight, BMI, waist volume $(r=0,37 ; p=0,007 ; r=0,62 ; p=0,000001$ and $\mathrm{r}=0,56 ; \mathrm{p}=0,00001$ respectively). The IL- 6 positively correlated with body weight, BMI and volume of a waist $(r=0,37 ; p=0,007 ; r=0,51$; $\mathrm{p}=0,00007$ and $\mathrm{r}=0,41 ; \mathrm{p}=0,002$ respectively). Besides, the leptin is associated with pain, health and an assessment of an illness the doctor on a scale VAS, and also about KOOS symptoms $(\mathrm{r}=0,40 ; \mathrm{p}=0,003$; $\mathrm{r}=0,29 ; \mathrm{p}=0,032$ and $\mathrm{r}=0,43 ; \mathrm{p}=0,001 ; \mathrm{r}=-0,27 ; \mathrm{p}=0,045$ respectively). Also, the leptin negatively associated with expressiveness of pain on scale SF-36 $(r=-0,38 ; p=0,004)$. Between the IL- $1 \beta$ and KOOS symptoms established negatively correlation $(\mathrm{r}=-0,28 ; \mathrm{p}=0,039)$. The IL- 6 associated with pain on a scale VAS $(r=-0,30 ; p=0,028)$. Also in the general group of patients with combination OA and T2DM were established negative correlation between IL-10 and general health on a scale VAS $(r=-0,36 ; p=0,007)$, and between $\mathrm{NO}$ and general state on scale SF-36 ( $r=-0,29 ; \mathrm{p}=0,035)$.

Taking into glucose blood level less than $6 \mathrm{mM} / \mathrm{L}$ in group OA and T2DM the association of the IL- $1 \beta$ with the general health on a scale VAS, and also the IL-10 with pain on KOOS scale is shown $(r=0,82$; $\mathrm{p}=0,023)$. In group OA and T2DM with glucose blood level higher than $6 \mathrm{mM} / \mathrm{L}$ the leptin correlated with expressiveness of pain, the general health and morning stiffness on a scale VAS $(r=0,33 ; p=0,025$; $\mathrm{r}=0,33 ; \mathrm{p}=0,025$ and $\mathrm{r}=0,39 ; \mathrm{p}=0,007$ respectively), pain on scale SF-36 (to $r=-0,30 ; p=0,041$ ). The IL- $1 \beta$ associated with pain on KOOS scale $(\mathrm{r}=-0,33 ; \mathrm{p}=0,023)$, the IL-10 - with the general health on a scale VAS $(r=0,40 ; p=0,005)$, and the IL- 6 - with pain on a scale VAS and physical functioning on scale SF-36 $(r=0,32 ; p=0,03$ and $r=-0,41 ; p=0,005$ respectively). CRP correlates with morning stiffness on scale VAS, physical functioning and mental health by a scale of SF-36 $(r=-0,30$; $\mathrm{p}=0,04 ; \mathrm{r}=0,37 ; \mathrm{p}=0,01$ and $\mathrm{r}=-0,43 ; \mathrm{p}=0,002$ respectively).

Under blood level of $\mathrm{Hgb} \mathrm{Alc}$ in patients with combination OA and T2DM was also established correlations between leptin and pain, the general health and an assessment of pain the doctor on a scale VAS, and with symptoms on a scale KOOS and pain on scale SF-36 $(\mathrm{r}=0,44$; $\mathrm{p}=0,008 ; \mathrm{r}=0,37 ; \mathrm{p}=0,025 ; \mathrm{r}=0,51 ; \mathrm{p}=0,001 ; \mathrm{r}=-0,42 ; \mathrm{p}=0,011$ and $\mathrm{r}=0,37$; $\mathrm{p}=0,024$ respectively). Moreover, in patients with combination $\mathrm{OA}$ and T2DM whom has Hgb A1c higher than 8\% level of leptin correlated with an illness assessment by the doctor on a scale VAS $(r=0,48$; $\mathrm{p}=0,049)$; with quality of life on KOOS scale $(\mathrm{r}=-0,48 ; \mathrm{p}=0,046)$; with pain and intensity of pain on scale SF-36 $(r=-0,53 ; p=0,027$ and $r=-$ 0,$49 ; p=0,018$ respectively). The IL- $1 \beta$ is associated with mental health on scale SF-36 $(r=0,63 ; p=0,006)$. Between the IL-10 and pain, mental health on a scale of SF-36 the negative correlations are revealed $(r=-$ 0,$53 ; \mathrm{p}=0,027$ and $\mathrm{r}=-0,50 ; \mathrm{p}=0,038$ respectively). The IL- 6 associated with morning stiffness on a scale VAS $(r=0,49 ; \mathrm{p}=0,043)$, pain and its intensity, and also mental health on scale SF-36 $(r=-0,70 ; p=0,0016 ; r=-$ 0,$68 ; \mathrm{p}=0,002$ and $\mathrm{r}=-0,56 ; \mathrm{p}=0,017$ respectively).

\section{Discussion}

Osteoarthrosis is a heterogeneous group of the diseases of various etiology having the general biological, morphological and clinical manifestations caused by defeat of all components of a joint as a result of violation the reparative processes in a subchondral bone and cartilaginous tissue [10-12].

It is shown that in pathogenesis of OA not only aging and mechanical damage of cartilaginous tissue, but, most likely, metabolic frustration which can initiate $\mathrm{OA}$ [13]. The metabolic syndrome 
including a hypertension and T2DM is often combined at elderly people with OA of a knee joint [14].

Violation of a metabolism and structure of a cartilage at OA amplifies cytokines (IL-1 $\beta$, TNF- $\alpha$ ), MMP (a collagenase, srtomelysin), and reparative processes - growth factors (IGF, TGF $\beta$ ) [8,11]. With an arterial hypertension or T2DM are characteristic of patients with OA statistically significant reduction of thickness of a bone in a subchondral zone of a knee joint, and also reduction of mineral density in comparison with patients with the isolated OA [14]. In patients with T2DM are revealed increases levels of the IL- $1 \beta$, TNF- $\alpha$ in blood serum $[2,15]$.

The combination of OA and T2DM leads to change of functional activity of chondrocytes. So, at stimulation of chondrocytes, obtained from patients with combination OA and T2DM, by IL- $1 \beta$ increases the level of production of IL- 6 and PGE in comparison with chondrocytes from patients with $\mathrm{OA}$ without violation of a carbohydrate exchange. At the level of expression by chondrocytes mRNA of IL- 6 and COX-2, and at the level of production IL-6, and PGE, and NO can influence the level of glucose in culture media. The production of IL-6 by chondrocytes rapidly decreased under addition in culture media Cytochalasin B (the glucose transport inhibitor) [16]. Authors [17], demonstrated effect of glucose levels in culture media on human chondrocytes functional activity. So, they indicated increased of mRNA MMP1 and MMP 13 levels by chondrocytes from patients with $\mathrm{OA}$, and only increased MMP 1 levels in chondrocytes obtained from healthy man. This finding indicates at the strengthening of catabolic processes in cartilaginous tissue and, thereby, to confirm weighting of inflammatory and degenerate processes in patients with combination of OA and T2DM.

It is known that the hyperglycemia is connected with risk of development of OA. In patients with hyperglycemia increased formation AGE (product of interaction of glucose with free amino-acid remains in proteins), especially in the tissues enriched with collagen that leads to mechanical and biomechanical change of tissues including a cartilage [18].

The course of OA at patients with T2DM differs from that at patients with OA without T2DM. For patients with combination of $\mathrm{OA}$ and T2DM are typically obesity, more expressed changes of the functional status and quality of life in comparison with patients with sick OA without violations of a carbohydrate exchange. Moreover, in patients with combination of OA and T2DM observed higher serum levels of IL-6, IL-18, NO and leptin compared to patient with OA alone.

In our study we showed that in patients with combination of OA and T2DM whom has glucose blood level lower than $6 \mathrm{mM} / \mathrm{L}$ and $\mathrm{Hgb}$ A1c lower than $8 \%$ are typically smaller duration of illness and expressiveness of violation of functional activity of joints, qualities of life that indirectly indicates an involvement of violations of a carbohydrate exchange into pathogenesis of OA.

The revealed increase in blood serum in patients with combination of OA and T2DM levels of pro-inflammatory cytokines (IL-6, IL-18) doesn't contradict literary data on increase in their contents at OA, indicates activation of degenerate and inflammatory processes in bodies and tissues [8]. NO is considered as the indicator of inflammatory processes and collects at damage of tissues. Existence of association with the IL-1 $\beta$, IL- 6 and IL-10 levels testifies to an involvement of cytokines into pathogenesis of OA. Moreover, in patients with combination of OA and T2DM the higher levels of leptin didn't contradict the literary data indicating his increasing in patients with T2DM, OA, especially at persons with excess body weight [19-21]. We have shown the presence of association of leptin with the functional status and quality of life in patients with combination of OA and T2DM that indirectly confirms a role of leptin in pathogenesis of a disease.

\section{Conclusion}

Thus, patients with combination $\mathrm{OA}$ and $\mathrm{T} 2 \mathrm{DM}$ are characterized by heavier course of inflammatory and degenerate processes in cartilaginous tissue in joints. The hyperglycemia, excess body weight initiated an inflammation, a progression of a degeneration of cartilaginous tissue.

\section{Competing interest}

The authors declare that they have no competing interests.

\section{Authors' contributions}

AP Lykov carried out the immunoassay, performed statistical analysis, wrote the paper. EP Trifonova enrolled patients, collected blood serum samples. OV Sazonova enrolled patients, examined clinical signs, conceived and designed experiments. EV Zonova participated in the design of the study and coordination and helped to draft the manuscript. All authors read and approved the manuscript.

\section{Acknowledgements}

We wish to thanks Ekaterina A Lykova for help with wrote the paper.

\section{References}

1. Sena CM, Bento C, Pereira P, Seica R (2010) Diabetes mellitus: new challenges and innovative therapies. EPMA J 1: 138-163.

2. Butcher MJ, Hallinger D, Garcia E, Machida Y, Chakrabarti S, et al. (2014) Association of proinflammatory cytokines and islet resident leucocytes with islet dysfunction in type 2 diabetes. Diabetologia 57: 491-501. [Crossref]

3. King KB, Rosenthal AK (2015) The adverse effects of diabetes on osteoarthritis: update on clinical evidence and molecular mechanisms. Osteoarthritis Cartilage. [Crossref]

4. Piva SR, Susko AM, Khoja SS, Josbeno DA, Fitzgerald GK, et al. (2015) Links between osteoarthritis and diabetes: implications for management from a physical activity perspective. Clin Geriatr Med 31: 67-87. [Crossref]

5. Trifonova ES, Korneva KG, Rakova GN, et al. (2012) The peculiarities of the course of osteoarthrosis of patients with the disorders of peripheral innervation of lower extremities at the background of diabetes mellitus type 2. Meditsinskiy Almanah 4: 92-94.

6. Schett G, Kleyer A, Perricone C, Sahinbegovic E, Iagnocco A, et al. (2013) Diabetes Is an Independent Predictor for Severe Osteoarthritis. Diabetes Care 36: 403-409. [Crossref]

7. de Lange-Brokaar BJ, Ioan-Facsinay A, van Osch GJ, Zuurmond AM, Schoones J, et al. (2012) Synovial inflammation, immune cells and their cytokines in osteoarthritis:a review. Osteoarthritis and Cartilage 20: 1484-1499. [Crossref]

8. Imamura M, Ezquerro F, Alfieri FM, et al. (2015) Serum Levels of Proinflammatory Cytokines in Painful Knee Osteoarthritis and Sensitization. Int J Inflammation.

9. Babak Aliarzadeh, Michelle Greiver, Rahim Moineddin, Christopher Meaney, David White, et al. (2014) Association between socio-economic status and hemoglobin A1c levels in a Canadian primary care adult population without diabetes. BMC Family Practice 15: 7-15.

10. Aleksenko EU, Govorin AV, Tsvinger SM (2010) Inflammatory markers in patients with osteoarthritis and arterial hypertension. Meditsinskaya Immunologiya 12: 429432 .

11. Korochina IE (2008) Determination of c-pept1de, serum insulin, and vales of tissue insulin resistance in patients with osteoarthrosis. Klinicheskaya Laboratornaya Diagnostika 7: 18-22. [Crossref] 
12. Shirinsky IV, Kalinovskaya NYu, Shirinsky VS (2015) Clinical and immunological characteristics of diabetes-associated osteoarthritis. Meditsinskaya Immunologiya 17: $87-92$.

13. Velasquez MT, Katz JD (2010) Osteoarthritis: another component of metabolic syndrome? Metab Syndr Relat Disord 8: 295-305. [Crossref]

14. Wen CY, Chen Y, Tang HL, Yan CH, Lu WW, et al. (2013) Bone loss at subchondral plate in knee osteoarthritis patients with hypertension and type 2 diabetes mellitus. Osteoarthritis and Cartilage 21: 1716-1723. [Crossref]

15. Chen FQ, Wang J, Liu XB, Ma XY, Zhang XB, et al. (2013) Levels of Inflammatory Cytokines in Type 2 Diabetes Patients with Different Urinary Albumin Excretion Rates and Their Correlation with Clinical Variables. J Diabetes Res: 138969. [Crossref]

16. Laiguillon MC, Courties A, Houard X, Auclair M, Sautet A, et al. (2015) Characterization of diabetic osteoarthritic cartilage and role of high glucose environment on chondrocyte activation: toward pathophysiological delineation of diabetes mellitus-related osteoarthritis.Osteoarthritis Cartilage 23: 1513-22. [Crossref]

17. Rosa SC, Rufino AT, Judas FM, Tenreiro CM, Lopes MC, et al. (2011) Role of glucose as a modulator of anabolic and catabolic gene expression in normal and osteoarthritic human chondrocytes. J Cell Biochem 112: 2813-2824. [Crossref]

18. Onur T, Wu R, Metz L, Dang A (2014) Characterisation of osteoarthritis in a small animal model of type 2 diabetes mellitus. Bone Joint Res 3: 203-211.

19. Kopylova DA, Ostapenko VA (2011) The clinical and pathogenetic features of obesityassociated osteoarthrosis. Klinicheskaya Laboratornaya Diagnostika 5: 28-31.

20. Coimbra S, Brandão Proença J, Santos-Silva A, Neuparth MJ (2014) Adiponectin, Leptin, and Chemerin in Elderly Patients with Type 2 Diabetes Mellitus: A Close Linkage with Obesity and Length of the Disease. BioMed Res Intern: 701915. [Crossref]

21. Chen X, Lu J, Bao J, Guo J, Shi J, et al. (2013) Adiponectin: a biomarker for rheumatoid arthritis? Cytokine Growth Factor Rev 24: 83-89. [Crossref]

Copyright: $@ 2016$ Zonova EV. This is an open-access article distributed under the terms of the Creative Commons Attribution License, which permits unrestricted use, distribution, and reproduction in any medium, provided the original author and source are credited. 